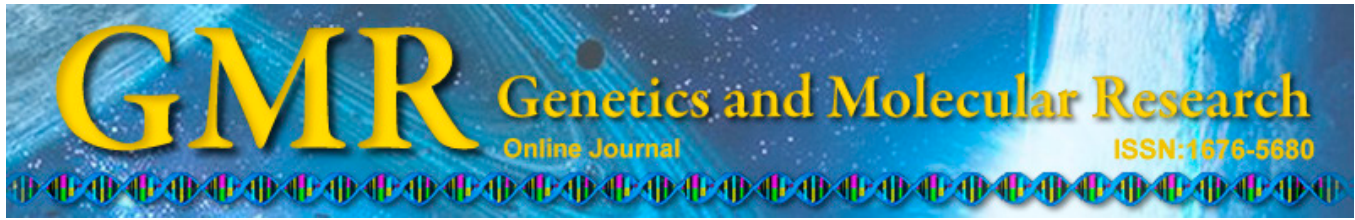

\title{
Dynamic QTL analysis of protein content and glutamine synthetase activity in recombinant inbred wheat lines
}

\author{
H.M. Li ${ }^{1,2}$, H. Liang', Z. Li ${ }^{1}$, Z.X. Tang', S.L. Fu', Y.Y. Geng' ${ }^{2}$, B.J. Yan ${ }^{1}$ \\ and Z.L. Ren ${ }^{1}$ \\ ${ }^{1}$ Sichuan Agricultural University, Chengdu, Sichuan, China \\ ${ }^{2}$ Hebei University of Engineering, Handan, Hebei, China \\ Corresponding authors: B.J. Yan / Z.L. Ren \\ E-mail: yanbenju@sicau.edu.cn / renzllab@sicau.edu.cn
}

Genet. Mol. Res. 14 (3): 8706-8715 (2015)

Received October 30, 2015

Accepted April 28, 2015

Published July 31, 2015

DOI http://dx.doi.org/10.4238/2015.July.31.19

\begin{abstract}
Protein content (PC) is a crucial factor that determines the end-use and nutritional quality of wheat (Triticum aestivum). Glutamine synthetase (GS), which is a major participant in nitrogen metabolism, can convert inorganic nitrogen into organic nitrogen. Although many studies have been conducted on PC and GS, a dynamic analysis of all of the filling stages has not been conducted. Therefore, $115 \mathrm{~F}_{9-10}$ recombinant inbred wheat lines of ' $\mathrm{R} 131 /$ R142' were used to analyze PC and GS activity during different developmental stages, using the conditional quantitative trait loci (QTL) mapping method. Twenty-two and six conditional QTL were detected for PC and GS activily, respectively. More QTL in leaf PC were detected during the early filling stages than in the later filling stages. Grain PC QTL displayed different dynamic variations to leaf PC QTL during the entire grain-filling stages. All of the QTL were expressed differently over time, and nine conditional QTL were detected across two filling stages. QTL with similar functions may have tended to group in specific locales. This study provides dynamic
\end{abstract}


genetic information on protein accumulation during grain-filling stages.

Key words: Wheat; Protein content; Conditional QTL; Glutamine synthetase; Dynamic QTL mapping

\section{INTRODUCTION}

Protein content (PC) is one of the main focuses of research into wheat breeding, because it is crucial in determining the quality of baked and boiled foods (bread, cookies, and noodles, etc.). It is very difficult to increase the PC in wheat because of its complex genetic system, and its sensitivity to the environment (Simmonds, 1995). To understand PC genetics at the molecular level, several studies have been conducted on PC quantitative trait loci (QTL), which have provided many valuable data for marker-assisted breeding (MAB) (Blanco et al., 1996; Prasad et al., 1999; Börner et al., 2002; Olmos et al., 2003).

During the grain-filling stage, a large number of amino acids from wheat leaves are transported into the grain and assembled into storage proteins. These storage proteins greatly affect wheat-processing quality, through protein synthesis and enrichment in the grain (Wang et al., 2008). Therefore, as the major organ in wheat nitrogen assimilation, the leaf (particularly the flag leaf) influences the final quality of the wheat product.

Enzyme content and activity are controlled by more than one gene during plant metabolism (Obara et al., 2001, 2004). For example, in addition to introducing a glutenin subunit gene, another gene is also needed to ensure its successful expression (Ren, 2002). In higher plants, ammoniacal nitrogen can be directly absorbed and assimilated into glutamic acid by glutamine synthetase (GS) and glutamate synthase, and finally converted into protein for biological activity (Ireland et al., 1999). Although GS plays a crucial role in converting inorganic nitrogen into organic nitrogen during nitrogen metabolism (Miflin and Habash, 2002), few studies have conducted a QTL analysis of GS (Sasaki et al., 2002; Limami et al., 2003; Obara et al., 2001, 2004).

Several QTL studies on wheat quality have been conducted; however, most have focused on a given period during the grain-filling stage (most at maturity), using traditional statistical analyses, and information on gene expression at different developmental stages is lacking (Han et al., 2011). Consequently, several studies have been conducted on developmental behavioral traits (Yan et al., 1998a; Li et al., 2010; Han et al., 2011; Zheng et al., 2011; Cui et al., 2012). Regarding dynamic QTL studies, Zhu (1995) suggested that conditional analyses are more powerful than unconditional analyses for ascertaining the gene expressions of quantitative developmental behavioral traits. Therefore, to elucidate the dynamic genetic mechanism involved, conditional analyses at different developmental stages should be conducted (Wang et al., 2008; Zheng et al., 2011).

Considering that 1 ) wheat protein accumulation during filling stages is a complex physicochemical process and cannot be completed in a single event, and 2) dynamic QTL analyses (particularly conditional analyses) are effective in evaluating the gene expressions of quantitative traits, in the present study the PC and GS activity (GSA) were studied during the filling stages, and the data were analyzed by conditional dynamic QTL analyses. Our aim was to understand the dynamic behavior of quantitative trait expression, and provide more desirable QTL for MAB (Han et al., 2011). 


\section{MATERIAL AND METHODS}

\section{Genetic material}

The population consisted of $115 \mathrm{~F}_{9-10}$ recombinant inbred wheat lines (RILs), which were derived from filial generations of the wheat (Triticum aestivum L.) lines R131 and R142. The flowering stage of the two parents was different by 3 days in 2010 [R131 (3/28), R142 (3/25), where $\mathrm{m} / \mathrm{n}$ mean month and day]. The flowering stage of the RILs was between $3 / 22$ and $4 / 1$, and $75.2 \%$ of them were between $3 / 25$ and $4 / 1$.

The RILs and their parents were planted with three replications in Qionglai District $\left(30^{\circ} 25^{\prime} \mathrm{N}, 103^{\circ} 28^{\prime} \mathrm{E}\right.$ and $493.3 \mathrm{~m}$ above sea level), Chengdu, Sichuan, China, between 2009 and 2010. Each plot was $3 \mathrm{~m}$ long and $25 \mathrm{~cm}$ apart, and contained two rows with 90 seeds in each row. The field management followed standard agricultural practice. At the flowering stage, 25 plants in each plot were marked with brands, and these marked plants had the same vigorous growth tendency and flowering stage. Flag leaves were harvested every 4 days from $4 / 5$ to $5 / 10$, and wheat ears were also harvested every 4 days from $4 / 15$ to $5 / 5$. All of the samples were stored at $-75^{\circ} \mathrm{C}$ for $2 \mathrm{~h}$.

Frozen wheat ears were fast-threshed to manually grain. Frozen leaves were fast-crushed by hand, and some were kept in a refrigerator for GSA analysis. The remaining leaves and grain were dried in a drying oven at $100^{\circ} \mathrm{C}$ for $5 \mathrm{~min}$, and $45^{\circ} \mathrm{C}$ for $10 \mathrm{~h}$, respectively. The fresh and dry weights of leaves and grain were measured using a moisture content (MC) assay. Dry grain and leaves were milled to powder by hand. Grain PC (GPC) was determined using a distillation unit (B-324, Buchi, Sweden). The GSA measurement was conducted as described previously (Rhodes et al., 1975; Kamachi et al., 1991; Miflin and Habash, 2002; Martin et al., 2006).

\section{Map construction and QTL detection}

DNA was isolated from fresh leaves at the seeding stage using the cetyltrimethylammonium bromide (CTAB) method (Maroof et al., 1984). Single-sequence repeat (SSR) primer pairs of Xwmc were catalogued in the GrainGenes database (http://wheat.pw.usda.gov). SSR analysis was conducted as described previously (Senior and Heun, 1993). QTL were analyzed by composite interval mapping (CIM), using Windows QTL Cartographer version 2.5 (http:// statgen.ncsu.edu/qtlcart/WQTLCart.htm). CIM was run using the forward regression method at a $10-\mathrm{cM}$ window size. Permutation tests were conducted with 1000 repetitions at a 1-cM walk speed, and a significance level set at 0.05 .

A consensus map was constructed using JoinMap ${ }^{\circledR} 4$ (Van Ooijen, 2006), with microsatellite markers (Xwmc, Xgwm, and Xbarc) from three sets of mapping data (Somers et al., 2004; Quarrie et al., 2005; Xue et al., 2008). The results of the QTL analysis were projected onto the consensus map using BioMercator 2.1 (Arcade et al., 2004). The major procedures of consensus map construction and QTL projection were executed based on the descriptions by Li et al. (2013a).

\section{Statistical analyses}

The conditional phenotypic values (the net genetic effects of genes) were obtained by QGA Station 2.0 (Chen et al., 2012), following a mixed-model approach (Zhu, 1995). Basic 
statistical analyses were conducted using the PASW statistical package, version 18.0 (http:// www.spss.com.hk/statistics/). The phenotypic correlations were calculated using Pearson's correlation, and significant differences were investigated using two-tailed tests. The coefficient of variation was calculated using the means and standard deviations of the results of three replications.

\section{RESULTS}

\section{PC and GSA analysis}

In three consecutive years, the GPC of parent R142 was 2.39\% higher than that of R131 (Table 1). The PC (leaves and grain) and GSA (leaves) of the RILs exhibited different trends at the filling stages (Table 2 and Figure 1). In addition, all the traits of the RILs at the different filling stages exhibited markedly variable means, high coefficient of variations, and various degrees of transgressive segregation (Table 2). The abundant heritable variance indicated that the RILs were suitable for QTL analysis and could breed a specific cultivar.

Table 1. Grain protein content of R131 and R142 over 3 years.
\begin{tabular}{lllll}
\hline Parent & \multicolumn{3}{c}{ Protein content (\%) } \\
\cline { 2 - 5 } & 2008 & 2009 & 2010 & 10.65 \\
M131 & 11.12 & 12.05 & 10.63 & $11.25^{*}$ \\
& 11.11 & 11.96 & 13.60 & $13.64 *$ \\
R142 & 13.56 & 13.79 & 13.46 & \\
& 13.19 & 14.24 & & \\
\hline
\end{tabular}

*Significant difference $(\mathrm{P}<0.01)$ between parents.

Table 2. Phenotypic values of protein content and glutamine synthetase activity for recombinant inbred lines (RIL) and their parents at grain-filling stages.

\begin{tabular}{|c|c|c|c|c|c|c|c|}
\hline \multirow[t]{2}{*}{ Trait } & \multirow{2}{*}{$\begin{array}{l}\text { Filling stage } \\
\text { (month/day) }\end{array}$} & \multicolumn{2}{|c|}{ Parent } & \multicolumn{4}{|c|}{ RIL population } \\
\hline & & $\mathrm{R} 131$ & $\mathrm{R} 142$ & Mean & Min & Max & $\mathrm{CV}$ \\
\hline \multirow[t]{8}{*}{ Leaf protein content $(\%)$} & $4 / 5$ & 19.73 & 21.43 & 21.54 & 14.05 & 30.72 & 11.80 \\
\hline & $4 / 10$ & 21.35 & 24.58 & 22.55 & 5.34 & 28.04 & 13.31 \\
\hline & $4 / 15$ & 15.70 & 14.97 & 17.37 & 12.33 & 23.19 & 12.99 \\
\hline & $4 / 20$ & 14.74 & 14.56 & 16.60 & 11.68 & 24.81 & 11.82 \\
\hline & $4 / 25$ & 19.61 & 18.71 & 18.07 & 9.97 & 25.50 & 14.82 \\
\hline & $4 / 30$ & 11.61 & 10.96 & 13.08 & 6.31 & 28.36 & 26.15 \\
\hline & $5 / 5$ & 9.37 & 8.21 & 8.29 & 3.24 & 14.57 & 28.77 \\
\hline & $5 / 10$ & 3.98 & 3.12 & 4.46 & 0.71 & 8.17 & 22.42 \\
\hline \multirow[t]{5}{*}{ Grain protein content $(\%)$} & $4 / 15$ & 8.82 & 11.08 & 11.37 & 8.82 & 14.43 & 9.72 \\
\hline & $4 / 20$ & 10.28 & 12.41 & 11.84 & 18.56 & 15.41 & 10.41 \\
\hline & $4 / 25$ & 11.02 & 11.48 & 11.77 & 8.21 & 23.15 & 16.95 \\
\hline & $4 / 30$ & 9.13 & 10.01 & 11.11 & 8.12 & 16.69 & 14.49 \\
\hline & $5 / 5$ & 10.40 & 11.02 & 11.07 & 8.14 & 14.19 & 11.03 \\
\hline \multirow[t]{7}{*}{ Glutamine synthetase activity } & $4 / 5$ & 0.78 & 0.55 & 0.74 & 0.47 & 2.34 & 27.13 \\
\hline & $4 / 10$ & 0.67 & 0.41 & 0.61 & 0.31 & 1.00 & 23.09 \\
\hline & $4 / 15$ & 0.48 & 0.66 & 0.74 & 0.26 & 3.04 & 39.27 \\
\hline & $4 / 20$ & 0.72 & 0.86 & 0.70 & 0.37 & 1.28 & 25.96 \\
\hline & $4 / 25$ & 0.25 & 0.43 & 0.46 & 0.19 & 0.85 & 30.94 \\
\hline & $4 / 30$ & & & 1.18 & 0.60 & 2.52 & 34.21 \\
\hline & $5 / 5$ & 1.28 & 1.87 & 1.37 & 0.50 & 2.79 & 31.20 \\
\hline
\end{tabular}

$\mathrm{CV}=$ coefficient of variation 

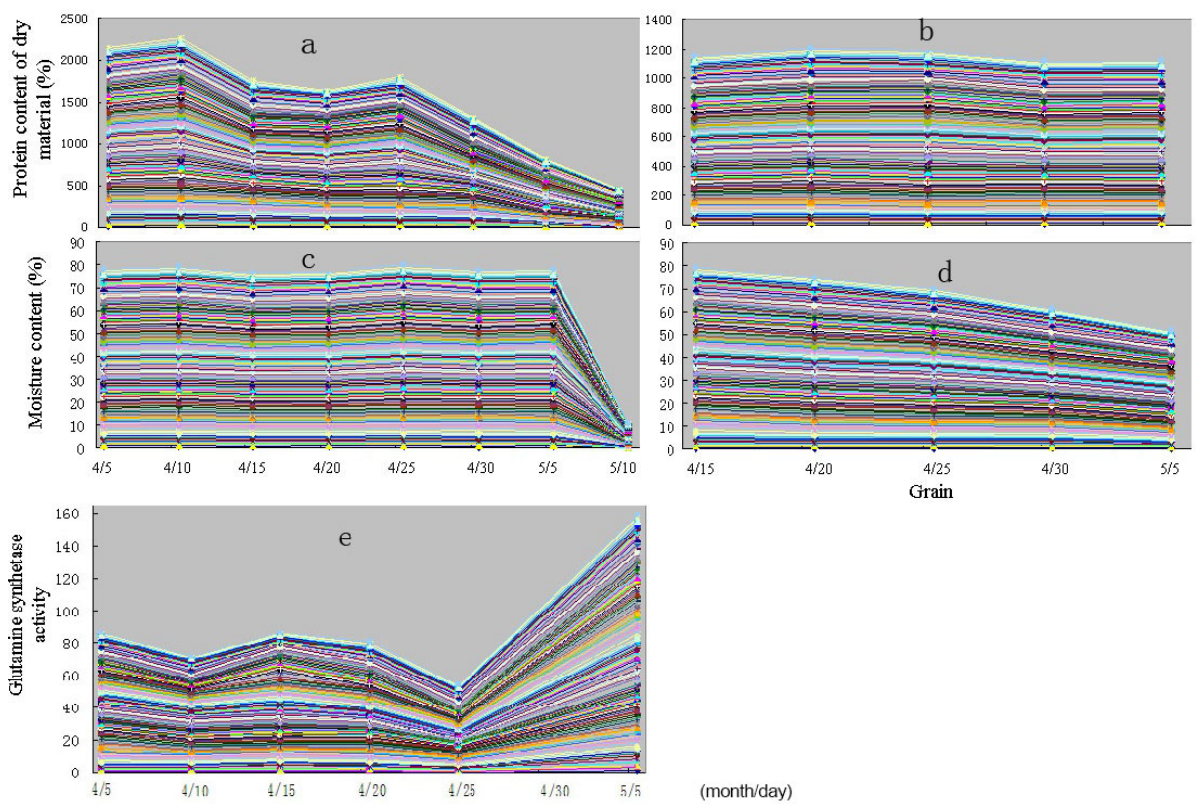

(month/day)

Figure 1. Accumulation line charts of protein content and glutamine synthetase activity in the R131 x R142 recombinant inbred wheat lines. a. Mean protein content of dry leaf; b. mean protein content of dry grain; c. mean moisture content of leaf; $\mathbf{d}$. mean moisture content of grain; e. mean glutamine synthetase activity of leaf.

The leaf PC (LPC) of R142 was higher than that of R131 during the period 4/5 to $4 / 10$, but the opposite pattern was found at the following filling stage. In the RILs and their parents, LPC generally declined, and only increased at 4/15-4/10 and 4/20-4/25, and decreased to a minimum on 5/10. R142 had higher GPC than R131. The GPC of the RILs was maintained at a stable level during the filling stages. During all of the filling stages, leaf MC kept at a steady level before decreasing sharply from $5 / 5$, while grain $\mathrm{MC}$ exhibited a steady decrease. This suggests that grain dry matter accumulated at a steady rate during the filling stages.

In the RILs and their parents, the GSA exhibited a fluctuating trend during the period $4 / 5-4 / 25$, and reached minima on $4 / 10$ and $4 / 25$. It increased rapidly from $4 / 25$ to $5 / 5$, and peaked on 5/5. This result indicates that QTL/gene expression has different time-phase - the expression level changes with time. The patterns of the changes in GSA were exactly opposite to those in LPC. This difference suggests that GS and LPC may be in the same enzymatic reaction system; the excess product (protein) would inhibit GSA.

\section{QTL analysis of PC and GSA}

Nine conditional QTL were detected in the GPC QTL analysis (Table 3 and Figure 2). There were three QTL on $1 \mathrm{~B}$ chromosome and two on $4 \mathrm{~B}$ chromosome. Three of the five GPC QTL (Q.GPC-1B.1, Q.GPC-4B.1, and Q.GPC-1B.3) were detected twice during the filling stages. Q.GPC-1B.1 was detected firstly at time $\mathrm{T}_{4}\left(\mathrm{LOD}=5.2, R^{2}=16.6\right)$, and its phenotypic variance was higher than that of the QTL detected the second time, $\mathrm{T}_{7} \cdot Q . G P C-4 B .1$ and $Q . G P C-1 B .3$ were detected twice in a series of time scales; they had opposite hereditary effects. 
There were more GPC QTL detected at the end of the filling stage; this meant that QTL expression related to grain filling had a temporal specificity, and became active at later filling stages.

Table 3. Conditional quantitative trait loci (QTL) for the grain protein content at different filling stages.

\begin{tabular}{|c|c|c|c|c|c|c|c|c|c|c|c|c|c|c|c|c|}
\hline \multirow[t]{2}{*}{$\overline{\text { QTL }}$} & \multirow[t]{2}{*}{ Marker interval } & \multicolumn{3}{|c|}{$\mathrm{T}_{3}(4 / 15)$} & \multicolumn{3}{|c|}{$\mathrm{T}_{4}(4 / 20 \mid 4 / 15)$} & \multicolumn{3}{|c|}{$\mathrm{T}_{5}(4 / 25 \mid 4 / 20)$} & \multicolumn{3}{|c|}{$\mathrm{T}_{6}(4 / 30 \mid 4 / 25)$} & \multicolumn{3}{|c|}{$\mathrm{T}_{7}(5 / 5 \mid 4 / 30)$} \\
\hline & & LOD & Add & $R^{2}$ & LOD & Add & $\overline{R^{2}}$ & LOD & Add & $\overline{R^{2}}$ & LOD & Add & $R^{2}$ & LOD & Add & $R^{2}$ \\
\hline Q.GPC-3B & Xwmc777-Xgwm566 & 3.2 & 0.294 & 6.2 & & & & & & & & & & & & \\
\hline Q.GPC-1B.1 & XWMC216-wmc216.3eb & & & & 5.2 & 0.753 & 16.6 & & & & & & & 9.8 & 0.176 & 1.7 \\
\hline Q. $G P C-2 D$ & Xgwm296-Xwmc25ys & & & & & & & 7.0 & 0.599 & 6.9 & & & & & & \\
\hline Q.GPC-4B.1 & Xwmc125-Xwmc349 & & & & & & & 6.9 & -0.681 & 9.2 & 3.4 & 0.202 & 1.4 & & & \\
\hline Q.GPC- $7 B$ & Xwmc273 & & & & & & & 6.5 & 0.561 & 5.7 & & & & & & \\
\hline Q. $G P C-2 A$ & Xwmc658-Xwmc179.2 & & & & & & & & & & 3.5 & -0.325 & 3.2 & & & \\
\hline Q.GPC-1B.2 & Xwmc419-Xwmc419x & & & & & & & & & & & & & 7.2 & 0.330 & 5.6 \\
\hline Q.GPC-1B.3 & Xwmc419x-Xwmc44 & & & & & & & & & & 3.5 & -0.183 & 1.0 & 8.2 & 0.271 & 3.8 \\
\hline Q.GPC-4B.2 & Xgwm251-Xwmc710 & & & & & & & & & & & & & 10.0 & 0.300 & 4.2 \\
\hline
\end{tabular}

$\left.\mathrm{T}_{\mathrm{n}} \mathrm{t} \mid \mathrm{t}-1\right)$ represents the conditional genetic effects from time ( $\left.\mathrm{t}-1\right)$ to $\mathrm{t}$ in the $n^{\text {th }}$ filling stage. $\mathrm{m} / \mathrm{n}=$ mean month/day.
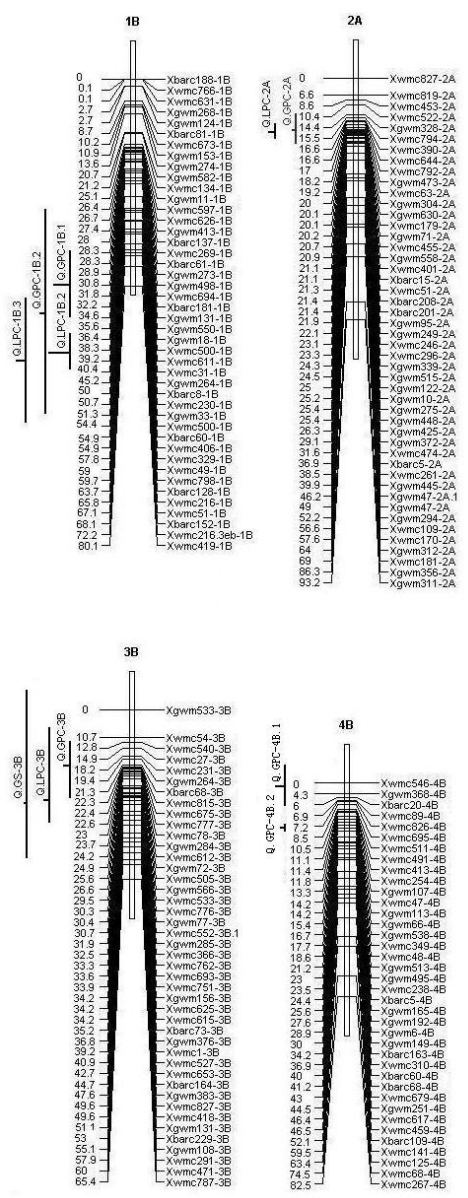
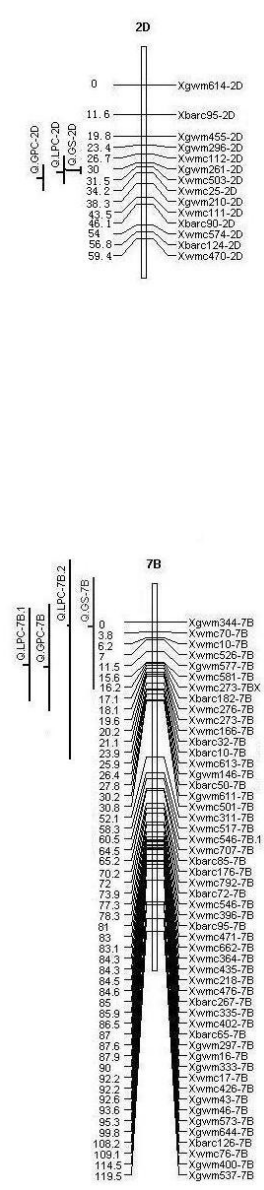

Figure 2. Positions of conditional quantitative trait loci associated with protein content and glutamine synthetase activity in the R131 x R142 recombinant inbred wheat lines. 
Thirteen QTL were detected in the conditional QTL analysis of wheat flag LPC, including four QTL on 1B, one on 2B, and one on 7B (Table 4). Q.LPC-2B.1 and Q.LPC-1B.2 had high phenotypic variance $\left(R^{2}>28 \%\right)$, and were detected twice at the grain-filling stages. Q.LPC-7B.1 and Q.LPC-1B.1 were also detected twice. Interestingly, Q.LPC-7B.1 was detected at an early $\left(\mathrm{T}_{2}\right)$ and a later period $\left(\mathrm{T}_{7}\right)$. Most of the LPC QTL were detected at an early stage of the grain-filling stages, but no LPC QTL were detected at $\mathrm{T}_{1}$ or $\mathrm{T}_{4}$. It is possible that $\mathrm{T}_{2}$ and $\mathrm{T}_{3}(10$ days $)$ is an important period, during which flag leaves produce and store protein.

Table 4. Conditional quantitative trait loci (QTL) for the protein content of wheat leaves at different filling stages.

\begin{tabular}{|c|c|c|c|c|c|c|c|c|c|c|c|c|c|c|c|c|}
\hline \multirow[t]{2}{*}{$\overline{\text { QTL }}$} & \multirow[t]{2}{*}{ Marker interval } & \multicolumn{3}{|c|}{$\mathrm{T}_{2}(4 / 10 \mid 4 / 5)$} & \multicolumn{3}{|c|}{$\mathrm{T}_{3}(4 / 15 \mid 4 / 10)$} & \multicolumn{3}{|c|}{$\mathrm{T}_{5}(4 / 25 \mid 4 / 20)$} & \multicolumn{3}{|c|}{$\mathrm{T}_{6}(4 / 30 \mid 4 / 25)$} & \multicolumn{3}{|c|}{$\mathrm{T}_{7}(5 / 5 \mid 4 / 30)$} \\
\hline & & $\overline{\text { LOD }}$ & Add & $\overline{R^{2}}$ & $\overline{\text { LOD }}$ & Add & $\overline{R^{2}}$ & $\overline{\text { LOD }}$ & Add & $\overline{R^{2}}$ & $\overline{\mathrm{LOD}}$ & Add & $\overline{R^{2}}$ & LOD & Add & $R^{2}$ \\
\hline Q.LPC-2B.1 & Xwmc500-Xwmc453b & 4.3 & 2.487 & 28.2 & & & & & & & 4.6 & 0.423 & 1.0 & & & \\
\hline Q.LPC-2B.2 & Xwmc453b-Xgwm148 & 7.9 & 0.972 & 9.0 & & & & & & & & & & & & \\
\hline Q. $L P C-7 D$ & Xwmc150.2-Xwmc438 & 8.4 & 0.845 & 5.2 & & & & & & & & & & & & \\
\hline Q.LPC-7B.1 & Xwmc273-Xwmc273x & 4.6 & -0.245 & 6.1 & & & & & & & & & & 3.9 & 0.502 & 3.4 \\
\hline Q.LPC-7B.2 & Xgwm344-Xwmc273 & 5.8 & 0.511 & 2.1 & & & & & & & & & & & & \\
\hline Q.LPC- $1 B .1$ & Xwmc216-Xwmc216.3eb & 5.7 & 0.552 & 2.1 & 4.0 & 0.575 & 3.3 & & & & & & & & & \\
\hline Q.LPC- $1 B .2$ & Xwmc419-Xwmc419x & 5.2 & 0.532 & 2.2 & 8.1 & -1.798 & 32.2 & & & & & & & & & \\
\hline Q. $L P C-2 D$ & Xwmc503S-Xgwm261 & & & & 4.0 & 0.674 & 7.2 & & & & & & & & & \\
\hline Q.LPC- $5 B$ & Xwmc73-Xwmc149x & & & & & & & 3.5 & -1.388 & 4.2 & & & & & & \\
\hline Q.LPC-1B.3 & Xwmc419x-Xwmc44 & & & & & & & & & & 5.0 & -1.169 & 9.0 & & & \\
\hline Q. $L P C-2 A$ & Xgwm294-Xgwm71 & & & & & & & & & & 5.9 & 0.957 & 6.5 & & & \\
\hline Q.LPC-3B & Xgwm376-Xwmc808 & & & & & & & & & & 5.4 & -0.843 & 5.5 & & & \\
\hline Q.LPC-1B.4 & Xgwm18-Xwmc406 & & & & & & & & & & & & & 3.6 & -0.458 & 3.4 \\
\hline
\end{tabular}

$\left.\mathrm{T}_{\mathrm{n}} \mathrm{t} \mid \mathrm{t}-1\right)$ represents the conditional genetic effects from time (t-1) to $\mathrm{t}$ in the $n^{\text {th }}$ filling stage. $\mathrm{m} / \mathrm{n}=$ month/day.

As GS is a key enzyme in nitrogen assimilation, it is important for wheat to accumulate enough protein. We detected six GSA QTL in wheat flag leaves using conditional QTL analysis (Table 5). Q.GSA-5B was detected twice at $\mathrm{T}_{1}$ and $\mathrm{T}_{3}$. Both Q.GSA-5B and Q.GSA-3B, detected at $\mathrm{T}_{1}$, had high LOD values $(>13)$. In addition, $Q . G S A-2 D$, which was detected at $\mathrm{T}_{2}$, had a high phenotypic variance $\left(R^{2}>29 \%\right)$. It is strange that GSA remained high at $\mathrm{T}_{4}$, but we did not detect QTL at this time (Table 5 and Figure 1a).

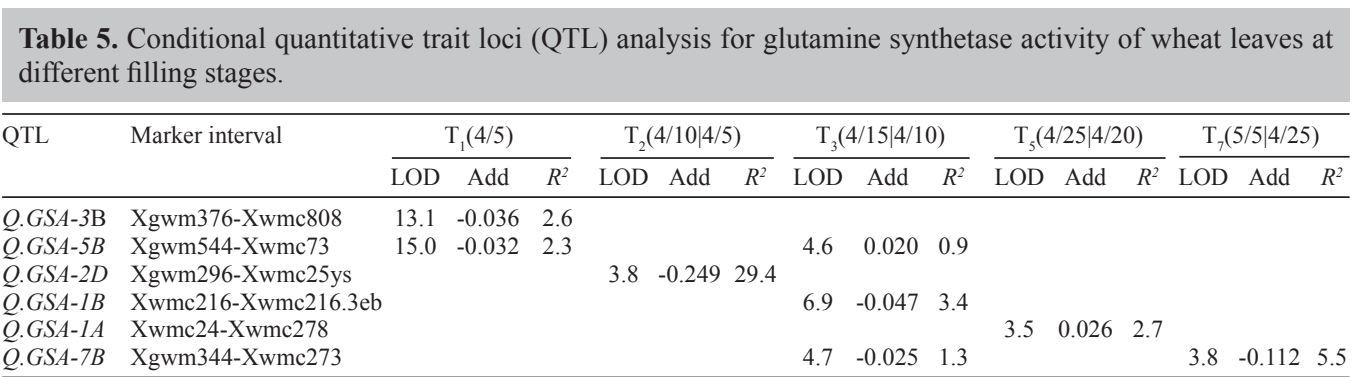

$\mathrm{T}_{\mathrm{n}}(\mathrm{t} \mid \mathrm{t}-1)$ represents the conditional genetic effects from time (t-1) to $\mathrm{t}$ in the $n^{\text {th }}$ filling stage. $\mathrm{m} / \mathrm{n}=$ mean month/day.

During the conditional QTL analysis of GPC, LPC, and GSA, the QTL of different traits were detected in the same molecular marker interval, which indicates that genes for these traits may co-localize in the same genomic location (Tables 3, 4, and 5). For example, 1) Q.GPC-1B.3 and Q.LPC-1B.3 were detected between the two molecular markers Xwmc419x 
and Xwmc44; and 2), Q.LPC-7B.2 and Q.GSA-7B were detected between the two molecular markers Xwmc344 and Xwmc273. This indicates that QTL with similar functions may gather in specific locales.

\section{DISCUSSION}

Genetic expression is closely related to trait development, which displays specific expression during ontogenetic development. Traditional QTL analysis is usually used for studying quantitative traits at a particular time, mainly during maturity (Wang et al., 2011; Li et al., 2013b; Park et al., 2013; Sandhu et al., 2013). As a static analysis method, it cannot accurately detect expressive QTL that correlate with GPC during all of the grain-filling stages, but can explain the accumulation effect, from expression to survey. Zheng et al. (2011) believe that dynamic QTL may be an effective method of revealing genetic information on protein accumulation during the grain-filling stages. By analyzing conditional genetic effects and variance components, Zhu (1995) perfected the precision of early dynamic QTL analysis, and obtained a net genetic variation value (phenotypic condition value) within the period (t-1) to t. Therefore, conditional QTL analysis can detect effective QTL, enhance our understanding of the time-dependent expression of QTL/genes, and provide information for MAB.

Some QTL of the three traits (GPC, LPC, and GSA) were detected twice, and exhibited the opposite genetic effect during the grain-filling stages. Other researchers have obtained similar results, which suggests that opposite genetic effects reduce differences in the accumulation effect and detection sensibility in unconditional QTL analysis (Yan et al., 1998b; Zheng et al., 2011). Yan et al. (1998a) reported that more tiller number QTL were detected by conditional QTL mapping than that by unconditional mapping. Therefore, conditional QTL analysis is a more efficient method for revealing the gene expression mechanisms of wheat at the filling stages. GSA was higher at $\mathrm{T}_{4}$ than at the other filling stages, but conditional QTL were not detected at $\mathrm{T}_{4}$, probably because the sampling interval was too long to separate the QTL by their opposite genetic effects (Yan et al., 1998a).

The conditional QTL analysis of PC and GSA revealed that the QTL of quantitative traits are expressed differently at different developmental stages. In this study, most QTL were detected at only one stage, and a few QTL were expressed in two continuous or separate stages. Sun et al. (2006) and Zheng et al. (2011) believe that this is the result of differential gene expression at different times. These results indicate that QTL/gene expression is timedependent during the entire developmental process.

In this study, some QTL of different traits were detected in the same molecular marker interval. Q.LPC-3B and Q.GSA-3B were in the molecular marker interval Xgwm376Xwmc808, and Q.LPC-7B.2 and Q.GSA-7B were in Xgwm344-Xwmc273. Q.GPC-1B.3 and Q.LPC-1B.3 were detected in Xwmc419x-Xwmc44, and Q.GPC-1B.3 was detected twice. These results demonstrate that QTL expression was time-specific, and QTL for similar traits tended to group in specific locales. Salih and Adelson (2009) stated that genes with similar functions may group in specific locales and contribute to QTL. Therefore, these locations must contain pleiotropic genes that control wheat-protein filling.

The LPC and GSA exhibited an oscillating and opposite trend at $\mathrm{T}_{2}$ to $\mathrm{T}_{5}$ (Figure 1). The probable reason for this is that GSA can promote protein accumulation in leaves during the filling stage, but is inhibited when the LPC reaches a certain level; when the LPC decreases by the nitrogen-transfer effect, the GSA increases again. From $\mathrm{T}_{6}$ to $\mathrm{T}_{7}$, the LPC decreased 
while the GSA rapidly increased. This may have been because the wheat was in a fast-filling stage, and the rate of nitrogen transfer from the leaves to the grain was increased. Similar, unusual enzyme activity was reported by Hänsch et al. (2006). Therefore, wheat has a complicated enzymatic reaction system. Enzymes, due to protein accumulation, can be inhibited by their own substrates, leading to velocity curve changes that gradually increase to a maximum as the substrate concentration decreases, and vice versa (Reed et al., 2010).

The QTL for the LPC were mainly detected during the early filling stages, $T_{2}$ and $T_{3}$ (Table 4), while the QTL for the GPC were found in the later stages, $\mathrm{T}_{5}, \mathrm{~T}_{6}$, and $\mathrm{T}_{7}($ Table 3 ). This suggests that wheat leaves store protein during the early filling stages. During these stages, PC genes are very active, and inorganic nitrogen is transformed into organic nitrogen in the leaves by assimilation. In the later filling stages, wheat leaves act as a protein source, and protein is transported from the leaves to the grain due to the high levels of gene expression in the grain. As can be seen in Figure 1, the last 10 to 15 days is an important period for filling, because QTL/ genes for the GPC are very active, and grain protein accumulates quickly during this period.

\section{ACKNOWLEDGMENTS}

Research supported by the National Natural Science Foundation of China (\#30730065, \#31271722), the National "973" Wheat Breeding Program, the Wheat Breeding Project of Sichuan Province, and the Initiatives of Sichuan Education Department for Wheat Breeding.

\section{REFERENCES}

Arcade A, Labourdette A, Falque M, Mangin B, et al. (2004). BioMercator: integrating genetic maps and QTL towards discovery of candidate genes. Bioinformatics 20: 2324-2326.

Blanco A, Giovanni C, Laddomada B, Sciancalepore A, et al. (1996). Quantitative trait loci influencing grain protein content in tetraploid wheats. Plant Breed. 115: 310-316.

Börner A, Schumann E, Fürste A, Cöster H, et al. (2002). Mapping of quantitative trait loci determining agronomic important characters in hexaploid wheat (Triticum aestivum L.). Theor. Appl. Genet. 105: 921-936.

Chen GB, Zhu ZX, Zhang FT and Zhu J (2012). Quantitative genetic analysis station for the genetic analysis of complex traits. Chin. Sci. Bull. 57: 2721-2726.

Cui F, Li J, Ding A, Zhao C, et al. (2012). QTL detection of internode length and its component index in wheat using two related RIL populations. Cereal Res. Comm. Doi: 10.1556/CRC.2012.0002.

Han Y, Xie D, Teng W, Zhang S, et al. (2011). Dynamic QTL analysis of linolenic acid content in different developmental stages of soybean seed. Theor. Appl. Genet. 122: 1481-1488.

Hänsch R, Lang C, Riebeseel E, Lindigkeit R, et al. (2006). Plant sulfite oxidase as novel producer of $\mathrm{H}_{2} \mathrm{O}_{2}$ combination of enzyme catalysis with a subsequent non-enzymatic reaction step. J. Biol. Chem. 281: 6884-6888.

Ireland RJ, Lea PJ and Singh B (1999). The enzymes of glutamine, glutamate, asparagine, and aspartate metabolism. Marcel Dekker, New York.

Kamachi K, Yamaya T, Mae T and Ojima K (1991). A role for glutamine synthetase in the remobilization of leaf nitrogen during natural senescence in rice leaves. Plant Physiol. 96: 411-417.

Li H, Tang Z, Zhang H, Yan B, et al. (2013a). Major quality trait analysis and QTL detection in hexaploid wheat in humid rain-fed agriculture. Genet. Mol. Res. 12: 1740-1751.

Li H-M, Liang H, Tang Z-X, Zhang H-Q, et al. (2013b). QTL analysis for grain pentosans and hardness index in a Chinese 1RS.1BL x non-1RS.1BL wheat cross. Plant Mol. Biol. Rep. 31: 477-484.

Li Z, Peng T, Xie Q, Han S, et al. (2010). Mapping of QTL for tiller number at different stages of growth in wheat using double haploid and immortalized F2 populations. J. Genet. 89: 409-415.

Limami A, Rouillon C, Glevarec G, Gallais A, et al. (2003). Genetic analysis and QTL mapping for cytosolic glutamine synthetase (GS) and germination traits in maize grain. In: The biology of seeds; recent research advances (Nicolas G, Bradford KJ, Come D and Pritchard H, eds.). CABI Publishing, Wallingford. 
Maroof MAS, Soliman KM, Jorgensen RA and Allard RW (1984). Ribosomal DNA spacer length polymorphisms in barley: Mendelian inheritance, chromosomal location, and population, and population dynamics. Proc. Natl. Acad. Sci. U. S. A. 81: 8014-8018.

Martin A, Lee J, Kichey T, Gerentes D, et al. (2006). Two cytosolic glutamine synthetase isoforms of maize are specifically involved in the control of grain production. Plant Cell 18: 3252-3274.

Miflin BJ and Habash DZ (2002). The role of glutamine synthetase and glutamate dehydrogenase in nitrogen assimilation and possibilities for improvement in the nitrogen utilization of crops. J. Exp. Bot. 53: 979-987.

Obara M, Kajiura M, Fukuta Y, Yano M, et al. (2001). Mapping of QTLs associated with cytosolic glutamine synthetase and NADH-glutamate synthase in rice (Oryza sativa L.). J. Exp. Bot. 52: 1209-1217.

Obara M, Sato T, Sasaki S, Kashiba K, et al. (2004). Identification and characterization of a QTL on chromosome 2 for cytosolic glutamine synthetase content and panicle number in rice. Theor. Appl. Genet. 110: 1-11.

Olmos S, Distelfeld A, Chicaiza O, Schlatter A, et al. (2003). Precise mapping of a locus affecting grain protein content in durum wheat. Theor. Appl. Genet. 107: 1243-1251.

Park KJ, Sa KJ, Koh HJ and Lee JK (2013). QTL analysis for eating quality-related traits in an F2:3 population derived from waxy corn x sweet corn cross. Breed. Sci. 63: 325-332.

Prasad M, Varshney R, Kumar A, Balyan H, et al. (1999). A microsatellite marker associated with a QTL for grain protein content on chromosome arm 2DL of bread wheat. Theor. Appl. Genet. 99: 341-345.

Quarrie SA, Steed A, Calestani C, Semikhodskii A, et al. (2005). A high-density genetic map of hexaploid wheat (Triticum aestivum L.) from the cross Chinese Spring $\mathrm{x}$ SQ1 and its use to compare QTLs for grain yield across a range of environments. Theor. Appl. Genet. 110: 865-880.

Reed MC, Lieb A and Nijhout HF (2010). The biological significance of substrate inhibition: a mechanism with diverse functions. Bioessays 32: 422-429.

Ren Z (2002). Several limiting factors of wheat production in south area of China and the new approach of wheat breeding. J. Sichuan Agric. Univ. 20: 299-303.

Rhodes D, Rendon G and Stewart G (1975). The control of glutamine synthetase level in Lemna minor L. Planta 125: 201-211.

Salih H and Adelson DL (2009). QTL global meta-analysis: are trait determining genes clustered? BMC Genomics 10: 1-8.

Sandhu N, Jain S, Kumar A, Mehla BS, et al. (2013). Genetic variation, linkage mapping of QTL and correlation studies for yield, root, and agronomic traits for aerobic adaptation. BMC Genetics 14: 104.

Sasaki S, Obara M, Kashiba K, Sato T, et al. (2002). Linkage analysis and characterization for QTL on chromosome 2 that associated with cytosolic glutamine synthetase content and panicle weight in rice (Oryza sativa L.). Plant Cell Physiol. 43: S71-S71.

Senior ML and Heun M (1993). Mapping maize microsatellites and polymerase chain reaction confirmation of the targeted repeats using a CT primer. Genome 36: 884-889.

Simmonds NW (1995). The relation between yield and protein in cereal grain. J. Sci. Food Agric. 67: 309-315.

Somers DJ, Isaac P and Edwards K (2004). A high-density microsatellite consensus map for bread wheat (Triticum aestivum L.). Theor. Appl. Genet. 109: 1105-1114.

Sun D, Li W, Zhang Z, Chen Q, et al. (2006). Quantitative trait loci analysis for the developmental behavior of soybean (Glycine max L. Merr.). Theor. Appl. Genet. 112: 665-673.

Van Ooijen JW (2006). JoinMap ${ }^{\circledR}$ 4, software for the calculation of genetic linkage maps in experimental populations (Kyazma BV, ed.). Wageningen.

Wang B, Zhu C, Liu X, Wang W, et al. (2011). Fine mapping of qHD4-1, a QTL controlling the heading date, to a 20.7-kb DNA fragment in rice (Oryza sativa L.). Plant Mol. Biol. Rep. 29: 702-713.

Wang H, Zhang W, Liu L, Shen Y, et al. (2008). Dynamic QTL analysis on rice fat content and fat index using recombinant inbred lines. Cereal Chem. 85: 769-775.

Xue S, Zhang Z, Lin F, Kong Z, et al. (2008). A high-density intervarietal map of the wheat genome enriched with markers derived from expressed sequence tags. Theor. Appl. Genet. 117: 181-189.

Yan J, Zhu J, He C, Benmoussa M, et al. (1998a). Quantitative trait loci analysis for the developmental behavior of tiller number in rice (Oryza sativa L.). Theor. Appl. Genet. 97: 267-274.

Yan J, Zhu J, He C, Benmoussa M, et al. (1998b). Molecular dissection of developmental behavior of plant height in rice (Oryza sativa L.). Genetics 150: 1257-1265.

Zheng L, Zhang W, Chen X, Ma J, et al. (2011). Dynamic QTL analysis of rice protein content and protein index using recombinant inbred lines. J. Plant Biol. 54: 321-328.

Zhu J (1995). Analysis of conditional genetic effects and variance components in developmental genetics. Genetics 141: 1633-1639. 